\title{
Antihyperlipidemic Potential of Polyphenol and Glycoside Rich Nerium oleander Flower against Triton WR-1339-Induced Hyperlipidemia in Experimental Sprague Dawley Rats
}

\author{
V. Gayathri, ${ }^{1}$ S. Ananthi, ${ }^{1}$ and Hannah R. Vasanthi ${ }^{2}$ \\ ${ }^{1}$ Department of Biotechnology, Mother Terasa Women's University, Kodaikanal 624102, India \\ ${ }^{2}$ Department of Biotechnology, School of Life Sciences, Pondicherry University, Puducherry 605014, India \\ Correspondence should be addressed to Hannah R. Vasanthi; hrvasanthi@gmail.com
}

Received 11 February 2012; Revised 2 May 2012; Accepted 31 May 2012

Academic Editor: Devanand Luthria

Copyright (C) 2013 V. Gayathri et al. This is an open access article distributed under the Creative Commons Attribution License, which permits unrestricted use, distribution, and reproduction in any medium, provided the original work is properly cited.

Nerium oleander Linn. (NO), an evergreen cardiac glycoside-rich shrub is used as folklore medicine in China to treat many diseases. It exhibits a wide spectrum of bioactivities but there were not much scientific reports on the bioactivity of $N$. oleander flowers. In the present study, we have evaluated the toxicity profile of the $50 \%$ hydroethanolic extracts of Nerium oleander flowers (ENO) using in vitro brine shrimp lethality assay and MTT cytotoxicity assay and in vivo acute toxicity test as per the OECD guidelines. The antihyperlipidemic activity of the ENO was also studied using Triton WR-1339-induced hyperlipemic rats and compared with standard Atorvastatin. In vitro brine shrimp, MTT cytotoxic assay, and in vivo acute toxicity assays showed a wide safety margin which has been evidenced through its lethal concentration $\left(\mathrm{LC}_{50}: 795.46 \mu \mathrm{g} / \mathrm{mL}\right)$ and growth inhibition $\left(\mathrm{GI}_{50}: 993.60 \mu \mathrm{g} / \mathrm{ml}\right)$ values. Plasma lipids and lipoproteins were significantly elevated by the intraperitoneal injection of Triton WR 1339 in hyperlipidemic rats at 6th and 24th hour. ENO pretreatment showed a significant ameliorative action on elevated lipids and lipoproteins in a dosedependent manner when compared to standard. Altogether, the results prove that Nerium oleander flowers are not toxic at the tested doses and exhibit antilipimic activity.

\section{Introduction}

World Health Organization (WHO), American Heart Associations, and epidemiologists around the globe have been pronouncing an alarm on the rapid increase in the burden of heart diseases for the past 20 years [1]. Experimental and epidemiological studies have shown that the plasma hyperlipidemic state could contribute to the development of atherosclerosis and cardiovascular-system-related diseases. Cardiovascular diseases (CVDs) are the most common cause of morbidity and mortality in many of the developing countries [2-4]. A logical strategy, to prevent or to treat atherosclerosis and reduce the incidence of cardiovascular disease events, is to target hyperlipidemia either by drugs or dietary intervention $[3,5]$. Based on this criterion, a number of plants have received attention and have been shown to lower plasma lipid levels [6]. Earlier studies also reveal that the consumption of polyphenols and glycosiderich compounds/plants will reduce the risk of hyperlipidemia [7-10].

Nerium oleander Linn is one such polyphenol- and glycoside-rich evergreen shrub belonging to the Apocynaceae, an important Chinese folk medicine [11]. In early times, it is assumed that all parts of the oleander plant are highly toxic to humans, animals, and certain insects due to the presence of cardiac glycosides mainly nerine and oleandrin at higher concentration $[12,13]$. Nowadays, apart from its toxicity, an assortment of pharmacological activities such as antinociceptive, anti-inflammatory, antibacterial, anticancer, CNS depressant activity, antidiabetic, rodenticides, piscicidal, pesticides, insecticides, abortifacients, among others, have been screened and reported in leaves, stems, and roots of Nerium oleander except flowers [14-18]. Apart cardiac glycosides, flowers of Nerium oleander 
contains triterpinoids, ursolic acid, steroids, polysaccharides, among others, reported to have various biological activities $[14,19,20]$. Moreover, our earlier finding confirms the presence of phytochemical constituents in N. oleander flower extract (ENO) [21] as well as the cardioprotective and antioxidant potential of ENO against isoproterenol-induced myocardial oxidative damage in experimental rats [22]. These findings prompted us to screen this investigation. Hence, in the present investigation, we have studied the toxicological profile and antihyperlipidemic potential of hydroethanolic extracts of Nerium oleander (ENO) flowers in experimental animals.

\section{Experimental}

\subsection{Materials}

2.1.1. Drugs and Chemicals. A549 cells were procured from Central Institute for Brackish water aquaculture with passage number 10 as a gift sample. Triton WR 1399 was obtained from Sigma Chemical Co., St. Louis, MO, USA. MTT (3-(4,5dimethylthiazolyl-2)-2,5-diphenyltetrazolium bromide) and DMEM were obtained from Himedia, Mumbai. Atorvastatin standard was obtained from a registered pharmacy, Sri Ramachandra Pharmacy, Chennai, India. Solvents and all other chemicals used were of analytical grade.

2.1.2. Plant Material. About $20 \mathrm{~kg}$ of fresh flowers of N. oleander (Apocynaceae) was obtained commercially in Chennai, Tamilnadu, and India. It was identified and authenticated by a qualified plant taxonomist Professor V. Jayaraman, Director, Plant Anatomy Research Centre, Tambaram, Tamilnadu, India. The flower was shade air dried and coarsely powdered. About $100 \mathrm{gm}$ of the powder was packed in a Soxhlet extractor with $500 \mathrm{~mL}$ of $50 \%$ ethanol and extraction was carried out for 18-20 h. The hydroethanolic extract (ENO) of Nerium oleander flower was concentrated to dryness under reduced pressure and controlled temperatures $\left(40-50^{\circ} \mathrm{C}\right)$ in a rotary flash evaporator. The powdered extract was stored in an air tight container and used for further studies.

2.1.3. Animals. Animal studies were executed after getting approval from the Institutional Animal Ethical Committee (IAEC XV/SRU/106/2009). Male Sprague-Dawley rats (150-250 gm) were obtained and maintained in the Central Animal Facility of Sri Ramachandra University, Porur, and Chennai, India. Experiments were carried out at the Centre for Toxicology and Development Research (CEFT) facility, Sri Ramachandra University, Chennai. Animals were housed in polypropylene cages at a room temperature of $21 \pm 2^{\circ} \mathrm{C}$ with $12 \mathrm{~h}$ light $/ 12 \mathrm{~h}$ dark cycles and had free access to standard pellets and water ad libitium.

\subsection{Methods}

2.2.1. Toxicological Profile. The toxicological profile of the hydroethanolic extracts of Nerium oleander (ENO) flowers using in vitro and in vivo methods was studied are as follows.

In Vitro Brine Shrimp Lethality Assay. Brine shrimp lethality bioassay was carried out according to the principle and protocol previously described by Nkengfack et al., [23]. In the experiment, $0.5 \mathrm{~mL}$ of the various concentration of ENO $(1.5-1000 \mu \mathrm{g} / 0.5 \mathrm{~mL})$ in triplicates was added to $4.5 \mathrm{~mL}$ of brine solution and maintained at room temperature for $24 \mathrm{~h}$ under the light and the surviving larvae were counted. Experiments were conducted along with control (vehicle treated). The percentage lethality was determined by comparing the mean surviving larvae of the test and control tubes. $\mathrm{LC}_{50}$ (concentration at $50 \%$ lethal effect) values were determined from the 24 hours count using the best-fit line probit analysis method described by Finney [24].

In Vitro Cytotoxicity Study: MTT Assay. The MTT assay was performed to study the antiproliferative effect of ENO using the earlier protocol [25, 26]. Lung adenocarcinoma cells (A549 Cells) were treated with different concentrations of ENO $(100-900 \mu \mathrm{g} / \mathrm{mL})$ for $24 \mathrm{~h}$. At the end of the treatment, media from control and drug-treated cells were discarded. $20 \mu \mathrm{L}$ of MTT containing DMEM $(0.5 \mathrm{mg} / \mathrm{mL})$ was added to each well. Cells were then incubated at $37^{\circ} \mathrm{C}$ for $4 \mathrm{~h}$ in a $\mathrm{CO}_{2}$ incubator. Spectrophotometrical absorbance of the purple blue formazan dye was measured using an ELISA reader (BIORAD) at $570 \mathrm{~nm}$. The average values were determined from the triplicate readings, and the average value was subtracted from the blank. The MTT reagent yields low background absorbance values in the absence of cells. Optical density of each sample was compared with control optical density and graphs were plotted. The plot of the data obtained in absorbance against number of cells provides a curve with a linear portion. Thus, both stimulation and inhibition of cell proliferation was measured. $\mathrm{GI}_{50}$ (50\% growth inhibition) values were determined from the maximum percentage of inhibition:

$$
\text { (\%) Inhibition }=\left[\frac{(\text { Abs. of control }- \text { Abs. of test })}{\text { Abs. of control }}\right] \times 100 \text {. }
$$

In Vivo Acute Oral Toxicity of ENO. The acute toxicity studies were performed in female Sprague Dawley rats as per the OECD guidelines-423. Acute toxicity was performed for three dose of ENO (50, 300, and $2000 \mathrm{mg} / \mathrm{kg}$ b.wt). The drug was suspended in $0.5 \% \mathrm{w} / \mathrm{v}$ sodium carboxyl methyl cellulose (CMC) and was prepared freshly each time. After the initial weights (150-200 g) were taken, the animals were distributed randomly into four groups ( $n=3$ /group) for conducting the study. Group I animals receiving the vehicle $(0.5 \% \mathrm{CMC})$ served as controls and Group II, III, and IV receiving ENO at 50, 300, and $2000 \mathrm{mg} / \mathrm{kg}$ b.wt, respectively. After a $12 \mathrm{~h}$ fast, the drugs were administered by intragastric route to all the animals. 
Animals were observed individually after drug dosing for signs and symptoms such as ataxia, tremors, sleep, coma, among others, at $0,0.5,1,2,4,6 \mathrm{hr}$ (with special attention) and then once a day for the next 14 days. Observations also included changes in respiratory, circulatory, autonomic and central nervous systems, as well as somatomotor activity (clinical findings such as ataxia, tremors, convulsion, hair loss, salivation, diarrhoea, lethargy, lacrimation, sleep, coma, etc.) and behaviour pattern. After drug administration, followed by measurement of body weight once in a week, any mortality and behavioral screenings were recorded for $24 \mathrm{~h}$ for the next 14 days. The results are expressed as mean \pm SEM of three animals.

\subsubsection{Antihyperlipidemia Triton WR-1399-Induced Hyperlipi-} demia. Hyperlipidemia was induced in experimental rats using Triton WR 1339 by following the earlier method [2729]. Triton (Superinone, Triton WR-1339), is a polymer of p-isooctylpolyoxyethylenephenol and formaldehyde, a nonionic surfactant. Aqueous solution of Triton WR 1399 was made in normal saline and injected at a dose of $250 \mathrm{mg} / \mathrm{kg}$., i.p. The test drug ENO doses 10, 30, and $100 \mathrm{mg} / \mathrm{kg}$ were selected as per the results obtained in our earlier studies $[21,22]$. Atorvastatin (ATV) tablet was used as a standard at a dose of $30 \mathrm{mg} / \mathrm{kg}$. All the drugs were suspended in $0.5 \% \mathrm{w} / \mathrm{v}$ sodium carboxyl methyl cellulose (CMC) and were prepared freshly each time. The drugs were administered by intragastric route.

Experimental Design. After the acclimatization period, animals were divided into nine groups of six rats each: Group I: Normal, Group II: Triton induction, Group III: Triton induction plus ATV (30 mg/kg/day, for 2 weeks) pretreated group, Group IV, V, VI: Triton induction plus ENO $(10 \mathrm{mg} / \mathrm{kg} /$ day, for 2 weeks) pretreated group, ENO $(30 \mathrm{mg} / \mathrm{kg} / \mathrm{day}$, for 2 weeks) pretreated group, ENO $(100 \mathrm{mg} / \mathrm{kg} /$ day, for 2 weeks) pretreated group respectively, Group VII: ENO $(100 \mathrm{mg} / \mathrm{kg} /$ day, for 2 weeks) alone treated group. After pretreatment with ENO and ATV for a period of 2 weeks, the animals were kept in wire-floored cages throughout the day to limit coprophagia. They were starved for 24 hours before the experiment but allowed free access to water [30]. Blood samples were collected from overnight fasted rats after $1 \mathrm{hr}$ after the last test drug treatment to respective groups for 0 th day.

After $1 \mathrm{hr}$ of initial blood collection $(0 \mathrm{hr})$ from respective groups, they were intraperitoneally injected with Triton WR $1339(250 \mathrm{mg} / \mathrm{kg})$ except Group I and VII animals. The body weight of the rats was individually recorded weekly once. Feed and water were changed every day. At the end of 6,24 , and 48th hr after injection of Triton WR-1339, all the rats were anesthetized for the blood collection. Blood was collected through sino-orbital puncture using EDTA as anticoagulant and the plasma separated was stored at $-80^{\circ} \mathrm{C}$ and used for the lipid and lipoprotein estimation.

Biochemical Analysis-Lipid profile on 0th, 6th, 24th, and 48th Hours. Total cholesterol (TC-Catlog number CL-2009-05001) and triglycerides (TG-Catlog and TG-2009-05-001) levels in plasma of 0th, 6th, 24th, and 48th hours were performed with enzymatic method of Accurex kit, Accrex Biomedical Pvt. Ltd., Thane, India using semiautomated biochemical analyzer (Star 21 Plus autoanalyser, Rapid Diagnostics).

HDL-cholesterol concentrations were quantified by the same method as used to determine total cholesterol after removal of other lipoproteins by precipitation with HDL precipitant (Accurex kit Catlog and HD-2009-05-001). The LDL and VLDL cholesterol was calculated by the Friedwald formula [31]:

$$
\begin{aligned}
& \text { LDL-Cholesterol } \\
& =(\text { total cholesterol } \\
& \quad \quad-[\text { HDL-Cholesterol + triglycerides } * 0.16])
\end{aligned}
$$

VLDL cholesterol $=$ Triglycerides $* 0.16$.

2.2.3. Statistical Analysis. All data are reported as mean \pm standard error mean (SEM). Statistical analysis was done using Graph pad prism 4.0 for windows package. One-way analysis of variance (ANOVA) was performed followed by post-hoc Tukey's test.The $P<0.05$ and $P<0.01$ values were set to access significant protection in treatment groups.

\section{Results}

3.1. Toxicological Profile. Figure 1 illustrated the in vitro toxicity profile of the ethanolic extract of $N$. oleander flower which was performed using Artemia nauplii (brine shrimp). Based on the ability of ENO to kill the laboratory-cultured brine shrimp, the toxic nature of ENO was identified. Maximum mortalities were obtained at a concentration of $1000 \mu \mathrm{g} / \mathrm{mL}$ whereas; low mortalities were seen at $30 \mu \mathrm{g} / \mathrm{mL}$ concentration. $\mathrm{LD}_{50}$ values were obtained from the best-fit line by plotting concentration verses percentage lethality in probit analysis.

Figure 2 gives an antiproliferative effect of ENO at various doses $(10-900 \mu \mathrm{g} / \mathrm{mL})$ against A549 cells (lung adenocarcinoma cell line) for $24 \mathrm{~h}$ using MTT assay. ENO exhibits a dose-dependant inhibitory effect on the growth of lung carcinoma cells and the growth inhibition of the cells $\left(R^{2}=0.958\right)$ is directly proportional to the dose. ENO exhibits greater cytotoxic effect against A549 cell at $900 \mu \mathrm{g} / \mathrm{mL}$ concentration with a $\mathrm{GI}_{50}$ value of $993.60 \mu \mathrm{g} / \mathrm{mL}$.

The in vivo toxicity profile of ENO was monitored after single oral administration of ENO to female rats at three doses 50, 300, and $2000 \mathrm{mg} / \mathrm{kg}$ b.wt, $(n=3 /$ dose $)$ for a period of 14 days. ENO at all doses did not show any remarkable change in the body weights of the rats (data not shown). There were no treatment-related mortality and clinical findings such as ataxia, tremors, convulsion, hair loss, salivation, diarrhoea, lethargy, lacrimation, sleep, coma, among others (data not shown). All experimental rats were found to be normal throughout the study. The $\mathrm{LD}_{50}$ of the ENO was found herein to be greater than $2000 \mathrm{mg} / \mathrm{kg}$ b.wt when administered once orally via gastric intubation in $12 \mathrm{~h}$ fasted female Sprague Dawley rats. 
TABLE 1: Effect of ENO and atorvastatin on total cholesterol and triglycerides in plasma of triton administered rats.

\begin{tabular}{lcccccc}
\hline \multirow{2}{*}{ Treatments } & \multicolumn{3}{c}{ T. cholesterol (mg/dL) } & \multicolumn{3}{c}{ Triglycerides (mg/dL) } \\
& 6th hr & 24th hr & 48th hr & 6th hr & 24th hr & 48th hr \\
\hline Normal Control (NC) & $110.12 \pm 5.53$ & $104.12 \pm 5.12$ & $83.30 \pm 3.44$ & $43.46 \pm 2.38$ & $41.46 \pm 1.98$ & $57.02 \pm 4.25$ \\
Triton (250 mg/kg, i.p) & $137.77 \pm 10.90^{\dagger}$ & $260.13 \pm 9.48^{\dagger \dagger}$ & $92.30 \pm 13.43$ & $153.88 \pm 14.03^{\dagger \dagger}$ & $431.30 \pm 36.26^{\dagger \dagger}$ & $101.02 \pm 5.95^{\dagger \dagger}$ \\
ATV (30 mg/kg, p.o) + Triton & $101.70 \pm 5.70^{* *}$ & $207.48 \pm 8.32^{* *}$ & $78.55 \pm 10.22$ & $100.76 \pm 12.27$ & $240.25 \pm 25.39^{* *}$ & $73.60 \pm 7.12^{*}$ \\
ENO (10 mg/kg, p.o ) + Triton & $96.94 \pm 5.04^{* *}$ & $238.04 \pm 11.41$ & $85.25 \pm 8.77$ & $130.49 \pm 17.05$ & $257.04 \pm 19.58^{* *}$ & $68.22 \pm 7.65^{* *}$ \\
ENO (30 mg/kg, p.o) + Triton & $90.94 \pm 6.08^{* *}$ & $234.04 \pm 11.55^{*}$ & $83.25 \pm 10.22$ & $127.83 \pm 16.81$ & $249.04 \pm 16.85^{* *}$ & $62.22 \pm 7.59^{* *}$ \\
ENO (100 mg/kg, p.o) + Triton & $112.17 \pm 5.33^{*}$ & $236.10 \pm 17.03$ & $80.84 \pm 11.91$ & $141.59 \pm 10.83$ & $257.28 \pm 13.27^{* *}$ & $59.06 \pm 4.76^{* *}$ \\
NC+ ENO (100 mg/kg, p.o) & $88.21 \pm 4.11$ & $86.92 \pm 3.72$ & $82.24 \pm 3.92$ & $33.75 \pm 2.00$ & $33.19 \pm 1.89$ & $34.18 \pm 2.26$ \\
\hline
\end{tabular}

The results are expressed in mean \pm SEM $(n=6)$; statistical analysis was done using prism 4.0 version, one-way ANOVA, tukey, and $P$ values normal control versus triton-treated rats and $\mathrm{NC}+\mathrm{ENO}$-treated rats- $-^{\dagger}(0.05)$ and ${ }^{\dagger \dagger}(0.01)$, triton-treated rats versus triton + atorvastatin and triton + ENO-treated rats${ }^{*}(0.05) \&{ }^{* *}(0.01)$.

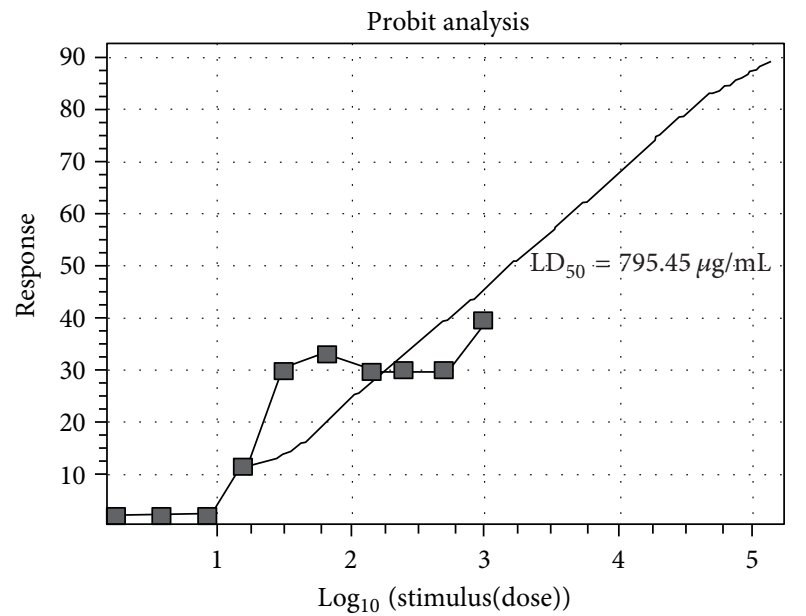

- Regression line
$\square-$ Experimental points

FIGURE 1: Brine shrimp lethality bioassay-probit analysis of ENO. Different concentrations of ENO $(1-1000 \mu \mathrm{g} / \mathrm{mL})$ was tested against brine shrimp for $24 \mathrm{~h}$.

3.2. Antihyperlipidemic Potential of ENO. In the current study, the antihyperlipidemic potential of ENO was also tested using male SD rats. Body weight of the rats was found to be insignificant in all the experimental groups (data not shown). The level of total cholesterol, triglycerides, HDL, LDL and VLDL at 0th, 6th, 24th, and 48th h of the triton induced and ENO treated animals were examined in plasma and all the results are shown in Tables 1 and 2, respectively. The levels of total cholesterol, triglycerides, LDL, and VLDL index were found to be normal at 0 th hour of all experimental animals before triton induction (Data not shown).

However, they were found to be significantly $(P<0.01)$ high at 6 th $\mathrm{h}$ after triton induction in the triton-induced untreated animals with concomitant decrease in HDL when compared to normal control animals. Similarly, at 24 th $\mathrm{h}$, the levels of total cholesterol, triglycerides, LDL, and VLDL were found to be at peak with decrease in HDL whereas at 48th h they were found to be nearer to normal in triton-induced untreated animals.

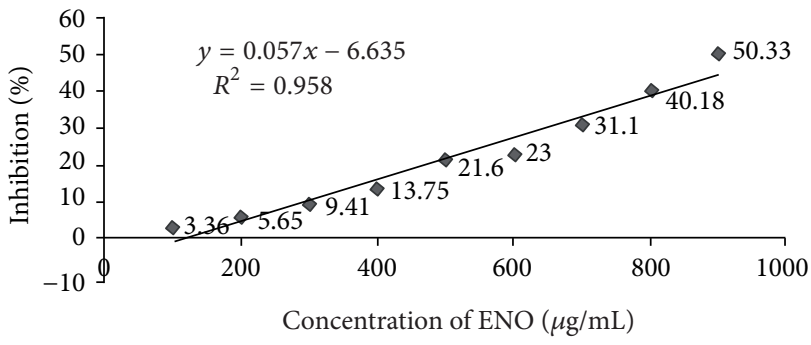

FIGURE 2: Cytotoxic effect of ENO on growth inhibition using A549 cells. Different concentrations of ENO $(100-900 \mu \mathrm{g} / \mathrm{mL})$ was tested against A549 cells for $24 \mathrm{~h}$. The values are Mean \pm SEM of triplicates $(n=3)$.

Rats pretreated with ENO (10, 30, and $100 \mathrm{mg} / \mathrm{kg}$ ) for 14 days significantly prevented the changes in lipid and lipoprotein levels in the plasma after triton induction compared to triton-induced untreated animals. The reduction in the total cholesterol, TGs, LDL, and VLDL levels by ENO was found to be in a dose-dependent manner and they were found to be comparable with Atorvastatin. Alternatively, the levels of lipid and lipoproteins in ENO $(100 \mathrm{mg} / \mathrm{kg})$ alone treated rats were found to be insignificant when compared to normal rats.

\section{Discussion}

Herbal drugs have been the integral part, in one form or another, of several indigenous therapeutic systems including traditional medicine and Indian System of Alternative Medicine [32]. Many numbers of medicinal plants and their active constituents play a role in the prevention and treatment of metabolic disorders like coronary heart disease and diabetes [33-35]. In traditional medicine, various parts of $N$. oleander have been used as a cardiotonic agent [36], rodenticides, piscicidal, pesticides, insecticides, and also used as remedies for indigestion, fever, ringworm, malaria, leprosy, venereal diseases, and as abortifacients [14]. In early times, all parts of the oleander are believed as poisonous to living things but off-late a number of pharmacological activities have been studied and reported by researchers [15]. Any compound to be considered as a drug toxicity studies 


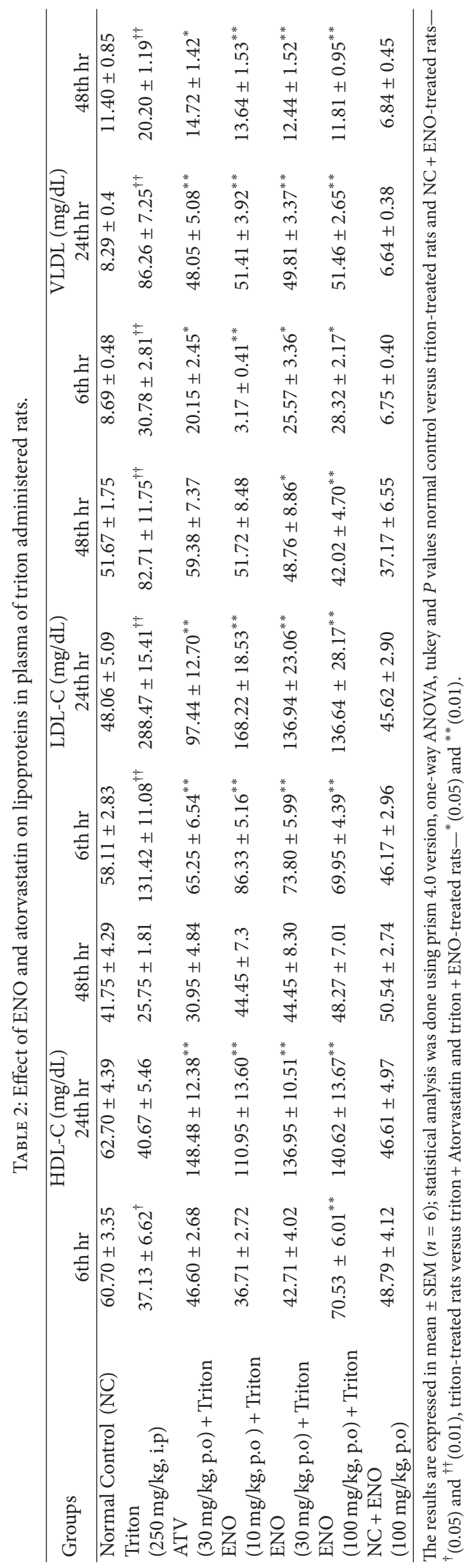


is imperative. Hence, assessment of the toxicity profile of $N$. oleander flower was considered a necessity.

In the present study, both in-vitro and in-vivo toxicity studies were done to identify the $\mathrm{LD}_{50}$ value of ENO and at which dose it is found to be nontoxic. Brine shrimp lethality bioassay which is considered as a useful tool for the assessment of toxicity of herbal extracts [37], in the present investigation the degree of lethality was found to be directly proportional to the concentration of the extract. The $\mathrm{LD}_{50}$ was found to be $795.46 \mu \mathrm{g} / \mathrm{mL}$ which reveals it is reduced toxicity against brine shrimps. Similarly, ENO exhibits a dose-dependant inhibitory effect against the growth of lung carcinoma cells A549 cells. The MTT cell proliferation assay measures the cell proliferation rate and conversely, the reduction in cell viability. The in vitro results concluded that the drug at lower concentrations is found to be safer but at higher concentrations it exhibits cytotoxic effect. This cytotoxic and antiproliferative effect of ENO at higher concentrations might be due to the presence of cardiac glycosides which further confirms its anticancer activity [38]. In a similar manner, ENO-treated animals were found to be normal throughout the study in in vivo acute toxicity study and its $\mathrm{LD}_{50}$ was found to be $>2000 \mathrm{mg} / \mathrm{kg}$ b.wt. These results summarizes that ENO possess a wide safety margin which has been evidenced through its $\mathrm{LD}_{50}$ and $\mathrm{GI}_{50}$ values.

Though there was a large class of hypolipidemic drugs available worldwide for the treatment, none of them is fully effective, absolutely safe, and free from side effects [39]. Hence, efforts are being made to find out safe and effective agents that may be beneficial in correcting the lipid metabolism and preventing cardiovascular diseases. Earlier, we have studied the cardioprotective and antioxidant potential ENO against isoproterenol-induced myocardial oxidative stress, ENO exhibits better free radical scavenging potential and cholesterol reducing activity [22]. Further, to validate the antihyperlipidemic property of ENO, triton WR-1339, a nonionic surfactant, was used in this study to induce hyperlipidemia in experimental animals and compared with standard atorvastatin, a potent lipid-lowering agent which inhibits an early step in the biosynthesis of cholesterol, thereby reducing the plasma cholesterol concentration. Their higher level may decrease the levels of triglycerides along with the cholesterol [40].

Stanley [41] suggested that intravenous or intraperitoneal injection of Triton WR 1339 increases hepatic cholesterol synthesis by increasing HMG CoA reductase activity, the first committed enzyme of the HMG-CoA reductase pathway in rodents within 24 hours which resulted in the increased plasma cholesterol and TG concentrations for upto $36 \mathrm{~h}$. Our results are in corroboration with that of previous reports [28, 42]. Triton causes structural modifications in the circulatory lipoproteins and suppress the action of lipases especially lipoprotein lipase activity and as a consequence block the uptake of circulating lipids by extra hepatic tissues, and, in turn, resulting in increased blood lipid concentration [29]. Significant increase in the level of cholesterol in the tritoninduced animals might also be due to the increased activity of $\mathrm{HMG}$ CoA reductase.
Triton induction was also reported to interact preferentially with HDL, changing the size and density of lipoproteins which used as substrates for the enzyme LCAT, enzyme activity decreased in parallel to the displacement of apo A1 [43]. In the present study, reduction in HDL-C in tritoninduced animals is agreeable with the earlier statement. In our study, the changes in plasma lipid and lipoprotein levels induced by triton WR-1339 can be resisted by ENO (10 and $30 \mathrm{mg} / \mathrm{kg})$ and atorvastatin $(30 \mathrm{mg} / \mathrm{kg})$ pretreatment during triton induction. Substantially, ENO treatment boosted the HDL levels at doses of 10, 30, and $100 \mathrm{mg} / \mathrm{kg}$ which might be through the inhibition of the activity of HMG CoA reductase and the stimulation of LCAT activity. Similarly, ENO results were found to be comparable with atorvastatin. Atorvastatin is a competitive inhibitor of $\mathrm{HMG}-\mathrm{CoA}$ reductase, our results corroborate with this statement.

Moreover, ENO was found to be rich in glycosides and polyphenols as evidenced by its concentration and characterization in our earlier investigations [21, 22]. Glycosides and polyphenolic compounds are reported to inhibit HMG CoA reductase activity [44-46]. Likewise, flavonoids may decrease the risk of cardiovascular disease by increasing the two ratios HDL/TG, HDL/LDL which may hasten removal of cholesterol from peripheral tissues to liver for catabolism and excretion $[7,9]$.

\section{Conclusion}

In conclusion, the results of the present study demonstrated that the ethanolic extract of $N$. oleander flower (ENO) was found to be safer at lower concentrations. The antihyperlipidemic activity of ENO is strengthened by its phytoconstituents and can be considered as a potent lipid-lowering and antioxidant agent. These beneficial activities may contribute to its cardio protective and antiatherosclerotic property.

\section{Acknowledgments}

The authors are grateful to the Department of Science and Technology, Government of India, for providing Junior Research Fellowship for V. Gayathri and S. Ananthi during the course of the study. They acknowledge the members of the Herbal and Indian Medicine Research Laboratory, Sri Ramachandra University, India, for their immense help in in vitro studies. They acknowledge the staff and the members of Center for Toxicology and Developmental Research (CEFT), Sri Ramachandra University, India, for their immense help in conducting animal studies at CEFT.

\section{References}

[1] S. Goenka, D. Prabhakaran, V. S. Ajay, and K. S. Reddy, "Preventing cardiovascular disease in India-translating evidence to action," Current Science, vol. 97, no. 3, pp. 367-377, 2009.

[2] J. M. Torpy, A. E. Burke, and R. M. Glass, "Neurofibromatosis," Journal of the American Medical Association, vol. 302, no. 19, p. 2170, 2009.

[3] H. Hicham, S. C. Hana, H. B. Nourel, A. Mohammed, and A Souliman, "Hypolipemic activity of polyphenol-rich extracts 
from Ocimum basilicum in Triton WR-1339-induced hyperlipidemic mice," Food Chemistry, vol. 108, no. 1, pp. 205-212, 2008.

[4] A. M. Diego, I. NebojsaIlic, P. Alexander, and R. Ilya, "Effects of Arachis hypogaea nutshell extract on lipid metabolic enzymes and obesity parameters," Life Sciences, vol. 78, no. 24, pp. 2797-2803, 2006.

[5] J. C. La Rosa, D. Hunninghake, D. Bush et al., "The cholesterol facts. A summary of the evidence relating dietary fats, serum cholesterol, and coronary heart disease. A joint statement by the American Heart Association and the National Heart, Lung, and Blood Institute," Circulation, vol. 81, no. 5, pp. 1721-1733, 1990.

[6] A. K. Khanna, F. Rizvi, and R. Chander, "Lipid lowering activity of Phyllanthus niruri in hyperlipemic rats," Journal of Ethnopharmacology, vol. 82, no. 1, pp. 19-22, 2002.

[7] I. Prassas and E. P. Diamandis, "Novel therapeutic applications of cardiac glycosides," Nature Reviews Drug Discovery, vol. 7, no. 11, pp. 926-935, 2008.

[8] J. Chen and X. Li, "Hypolipidemic effect of flavonoids from mulberry leaves in triton WR-1339 induced hyperlipidemic mice," Asia Pacific Journal of Clinical Nutrition, vol. 16, supplement 1, pp. 290-294, 2007.

[9] M. B. Engler and M. M. Engler, "The vasculoprotective effects of flavonoid-rich cocoa and chocolate," Nutrition Research, vol. 24, no. 9, pp. 695-706, 2004.

[10] M. Aviram, "Flavonoids-rich nutrients with potent antioxidant activity prevent atherosclerosis development: the licorice example," International Congress Series, vol. 1262, pp. 320-327, 2004.

[11] U. R. Desai, Cardiac glycosides. Virginia Commonwealth University School of Pharmacy, 2005.

[12] S. D. Langford and P. J. Boor, "Oleander toxicity: an examination of human and animal toxic exposures," Toxicology, vol. 109, no. 1, pp. 1-13, 1996.

[13] P. K. Mazumder, P. V. Lakshmana Rao, D. Kumar, S. N. Dube, and S. Das Gupta, "Toxicological evaluation of Nerium oleander on isolated preparations," Phytotherapy Research, vol. 8, no. 5, pp. 297-300, 1994.

[14] K. Ding, J. N. Fang, T. Dong, K. W. Tsim, and H. Wu, "Characterization of a rhamnogalacturonan and a xyloglucan from neriumindicum and their activities on PC12 pheochromocytoma cells," Journal of Natural Products, vol. 66, no. 1, pp. 7-10, 2003.

[15] V. Gupta and P. Mittal, "Phytochemical and Pharmacological Potential of Nerium oleander," International Journal ofPharmaceutical Sciences and Research, vol. 1, pp. 3-5, 2010.

[16] M. M. Yassin and S. N. Mwafy, "Protective potential of glimepiride and Nerium oleander extract on lipid profile, body growth rate, and renal function in streptozotocin-induced diabetic rats," Turkish Journal of Biology, vol. 31, no. 2, pp. 95-102, 2007.

[17] N Turan, K. Akgün-Dar, S. E. Kuruca et al., "Cytotoxic effects of leaf, stem and root extracts of Nerium oleander on leukemia cell lines and role of the p-glycoprotein in this effect," Journal of Experimental Therapeutics and Oncology, vol. 6, no. 1, pp. 31-38, 2006.

[18] N. Erdemoglu, E. Kupeli, and E. Yesilada, "Anti-inflammatory and antinociceptive activity assessment of plants used as remedy in Turkish folk medicine," Journal of Ethnopharmacology, vol. 89, no. 1, pp. 123-129, 2003.

[19] M. S. Yu, S. W. Lai, K. F. Lin, J. N. Fang, W. H. Yuen, and R. C. Chang, "Characterization of polysaccharides from the flowers of Nerium indicum and their neuroprotective effects,"
International Journal of Molecular Medicine, vol. 14, no. 5, pp. 917-924, 2004.

[20] M. S. Yu, A. Y. Wong, K. F. So, J. N. Fang, W. H. Yuen, and R. C. Chang, "New polysaccharide from Nerium indicum protects neurons via stress kinase signaling pathway," Brain Research, vol. 1153, pp. 221-230, 2007.

[21] V. Gayathri, S. Ananthi, C. Chandronitha, M. K. Sangeetha, and H. R. Vasanthi, "Hypolipidemic potential of flowers of Nerium oleander in high fat diet-fed Sprague Dawley rats," Natural Product Research, vol. 25, no. 11, pp. 1110-1114, 2011.

[22] V. Gayathri, S. Ananthi, C. Chandronitha, G. Ramakrishnan, R. L. Sundaram, and H. R. Vasanthi, "Cardioprotective effect of nerium oleander flower against isoproterenol-induced myocardial oxidative stress in experimental rats," Journal of Cardiovascular Pharmacology and Therapeutics, vol. 16, no. 1, pp. 96-104, 2011.

[23] A. E. Nkengfack, A. G. B. Azebaze, A. K. Waffo, Z. T. Fomum, M. Meyer, and F. R. Van Heerden, "Cytotoxic isoflavones from Erythrina indica," Phytochemistry, vol. 58, no. 7, pp. 1113-1120, 2001.

[24] D. J. Finney, Probit Analysis, Cambridge University Press, London, UK, 3rd edition, 1971.

[25] A. A. Van de Loosdrecht, R. H. Beelen, G. J. Ossenkoppele et al., "A tetrazolium-based colorimetric MTT assay to quantitate human monocyte mediated cytotoxicity against leukemic cells from cell lines and patients with acute myeloid leukemia," Journal of Immunological Methods, vol. 174, no. 1-2, pp. 311-320, 1994.

[26] F. F. Safadi, J. Xu, S. L. Smock et al., "Expression of connective tissue growth factor in bone: Its role in osteoblast proliferation and differentiation in vitro and bone formation in vivo," Journal of Cellular Physiology, vol. 196, no. 1, pp. 51-62, 2003.

[27] A. P. Kourounakis, P. Victoratos, N. Peroulis et al., "Experimental hyperlipidemia and the effect of NSAIDs," Experimental and Molecular Pathology, vol. 73, no. 2, pp. 135-138, 2002.

[28] K. A. Mitropoulos, G. J. Miller, D. J. Howarth, B. E. A. Reeves, and J. A. Cooper, "The effects of intravenous Triton WR1339 on factor VII coagulant activity and plasma lipoproteins in normocholesterolaemic and hypercholesterolaemic rabbits," Blood Coagulation and Fibrinolysis, vol. 5, no. 4, pp. 583-591, 1994.

[29] H. Hayashi, S. Niinobe, Y. Matsumoto, and T. Suga, "Effects of Triton WR-1339 on lipoprotein lipolytic activity and lipid content of rat liver lysosomes," Journal of Biochemistry, vol. 89, no. 2, pp. 573-579, 1981.

[30] T. Mizui and M. Douteuchi, "Effect of polyamines on acidified ethanol-induced gastric lesions in rats," Japanese Journal of Pharmacology, vol. 33, no. 5, pp. 939-945, 1983.

[31] W. T. Friedewald, R. I. Levy, and D. S. Fredrickson, "Estimation of the concentration of low-density lipoprotein cholesterol in plasma, without use of the preparative ultracentrifuge," Clinical Chemistry, vol. 18, no. 6, pp. 499-502, 1972.

[32] B. Patwardhan, D. Warude, P. Pushpangadan, and N. Bhatt, "Ayurveda and traditional Chinese medicine: a comparative overview," Evidence based Complementary and Alternative Medicine, vol. 2, pp. 465-473, 2005.

[33] P. Goldman, "Herbal medicines today and the roots of modern pharmacology," Annals of Internal Medicine, vol. 135, no. 8, pp. 594-600, 2001.

[34] B. M. Schmidt, D. M. Ribnicky, P. E. Lipsky et al., "Revisiting the ancient concept of botanical therapeutics," Nature Chemical Biology, vol. 3, no. 7, pp. 360-365, 2007. 
[35] T. H. Huang, B. P. Kota, and V. Razmovski, "Herbal or natural medicines as modulators of peroxisome proliferator-activated receptors and related nuclear receptors for therapy of metabolic syndrome," Basic and Clinical Pharmacology and Toxicology, vol. 96, no. 1, pp. 13-14, 2005.

[36] R. O. Adome, J. W. Gachihi, B. Onegi, J. Tamale, and S. O. Apio, "The cardiotonic effect of the crude ethanolic extract of Nerium oleander in the isolated guinea pig hearts," African Health Sciences, vol. 3, no. 2, pp. 77-82, 2003.

[37] J. L. McLauglin, C. J. Chang, and D. Smith, "Simple benchtop bioassays (brine shrimp and potato discs) for the discovery of plant antitumour compounds," in Human Medicinal Agents from Plants, A. D. Kinghorn and M. F. Balandrin, Eds., vol. 534 of ACS Symposium, pp. 112-137, American Chemical Society, Washington, DC, USA, 1993.

[38] S. Johansson, P. Lindholm, J. Gullbo, R. Larsson, L. Bohlin, and P. Claeson, "Cytotoxicity of digitoxin and related cardiac glycosides in human tumor cells," Anti-Cancer Drugs, vol. 12, no. 5, pp. 475-483, 2001.

[39] A. Ghatak and O. P. Asthana, "Recent trends in hyperlipoproteinemias and its pharmacotherapy," Indian Journal of Pharmacology, vol. 27, no. 1, pp. 14-29, 1995.

[40] K. K. Ray and C. P. Cannon, "The potential relevance of the multiple lipid-independent (Pleiotropic) effects of statins in the management of acute coronary syndromes," Journal of the American College of Cardiology, vol. 46, no. 8, pp. 1425-1433, 2005.

[41] G. Stanley, "Rapid increase in hepatic HMG CoA reductase activity and in vivo cholesterol synthesis after Triton WR 1339 injection," Journal of LipidResearch, vol. 19, pp. 1450-1461, 1978.

[42] A. Souliman, H. Hicham, G. Dounia et al., "Vasorelaxant and anti-platelet aggregation effects of aqueous Ocimum basilicum extract," Journal of Ethnopharmacology, vol. 125, no. 1, pp. 157-162, 2009.

[43] K. Yamamoto, B. Shen, C. Zarins, and A. M. Scanu, "In vitro and in vivo interactions of Triton 1339 with plasma lipoproteins of normolipidemic rhesus monkeys. Preferential effects on high density lipoproteins," Arteriosclerosis, vol. 4, no. 4, pp. 418-434, 1984.

[44] S. Sudheesh, G. Presannakumar, S. Vijayakumar, and N. R. Vijayalakshmi, "Hypolipidemic effect of flavonoids from Solanum melongena," Plant Foods for Human Nutrition, vol. 51, no. 4, pp. 321-330, 1997.

[45] S. M. Grundy, "Cholesterol and coronary heart disease. A new era," Journal of the American Medical Association, vol. 256, no. 20, pp. 2849-2858, 1986.

[46] P. M. Kris-Etherton, K. D. Hecker, A. Bonanome et al., "Bioactive compounds in foods: their role in the prevention of cardiovascular disease and cancer," American Journal of Medicine, vol. 113, supplement 9, pp. 71S-88S, 2002. 

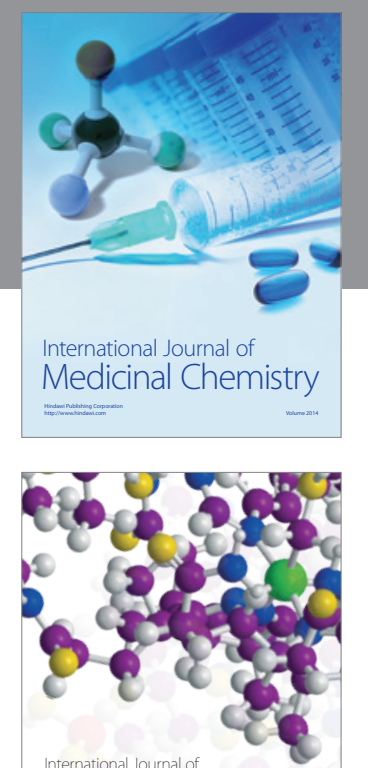

\section{Carbohydrate} Chemistry

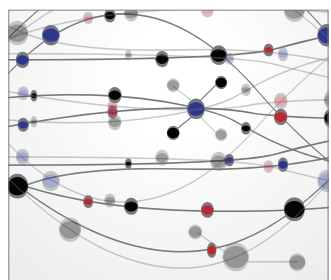

The Scientific World Journal
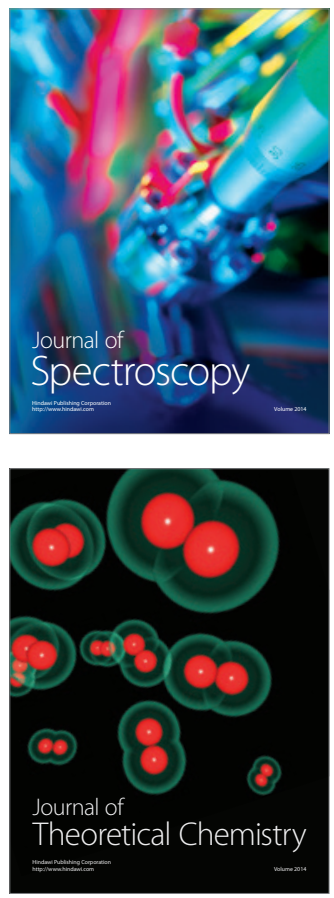
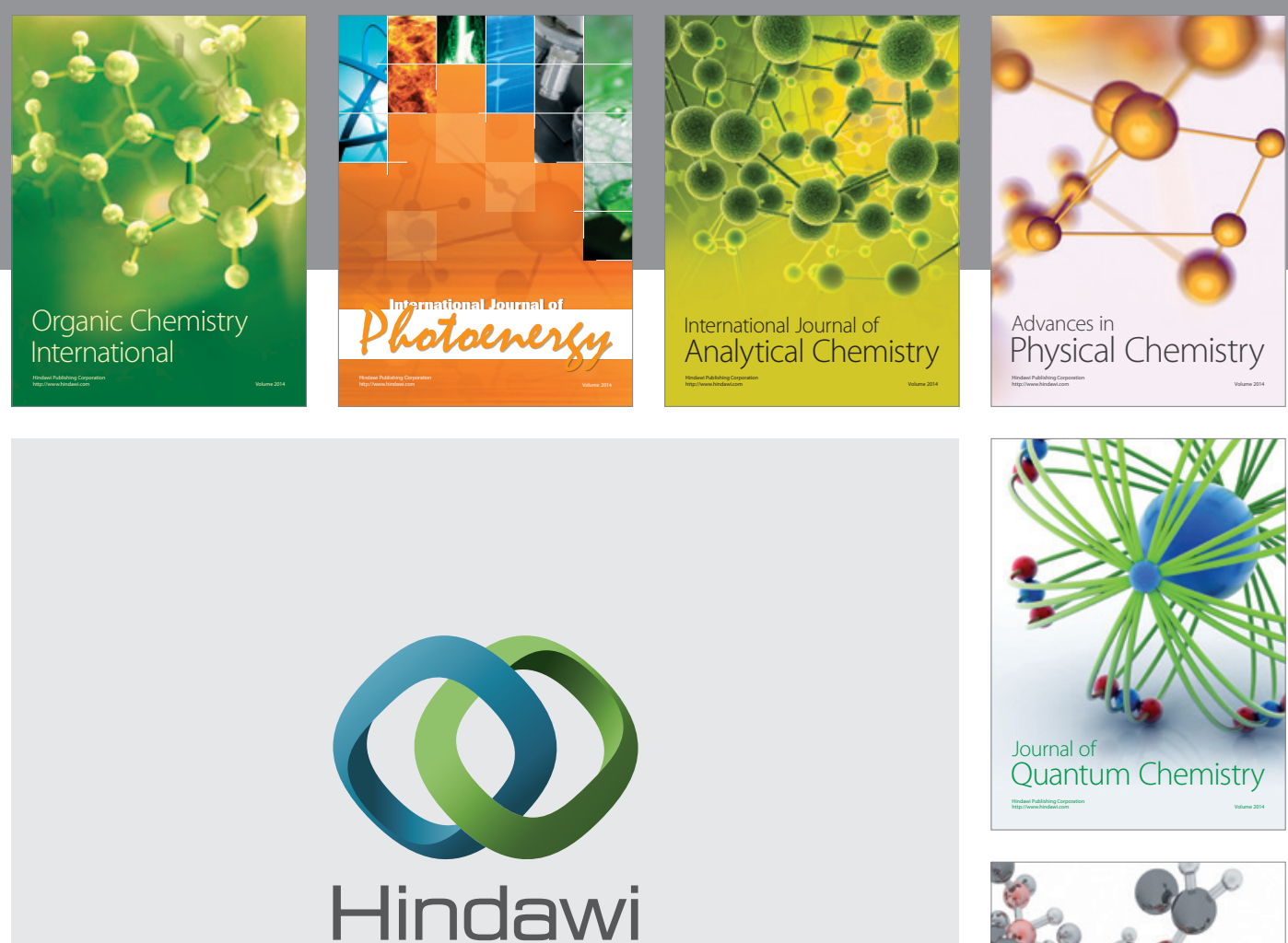

Submit your manuscripts at

http://www.hindawi.com

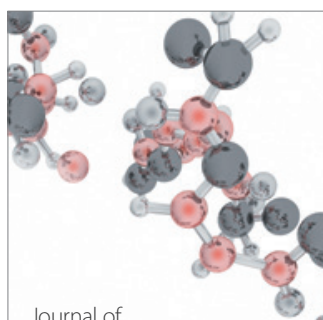

Analytical Methods

in Chemistry

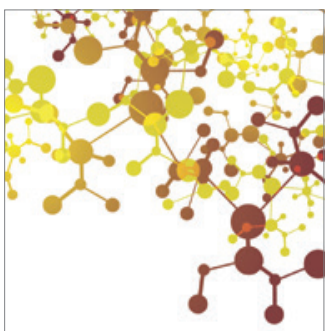

Journal of

Applied Chemistry

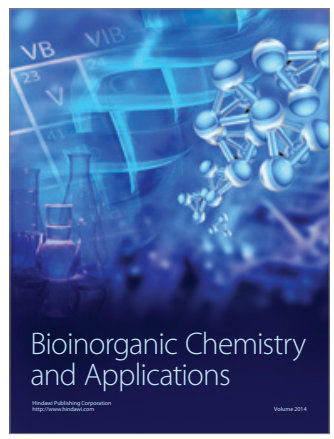

Inorganic Chemistry
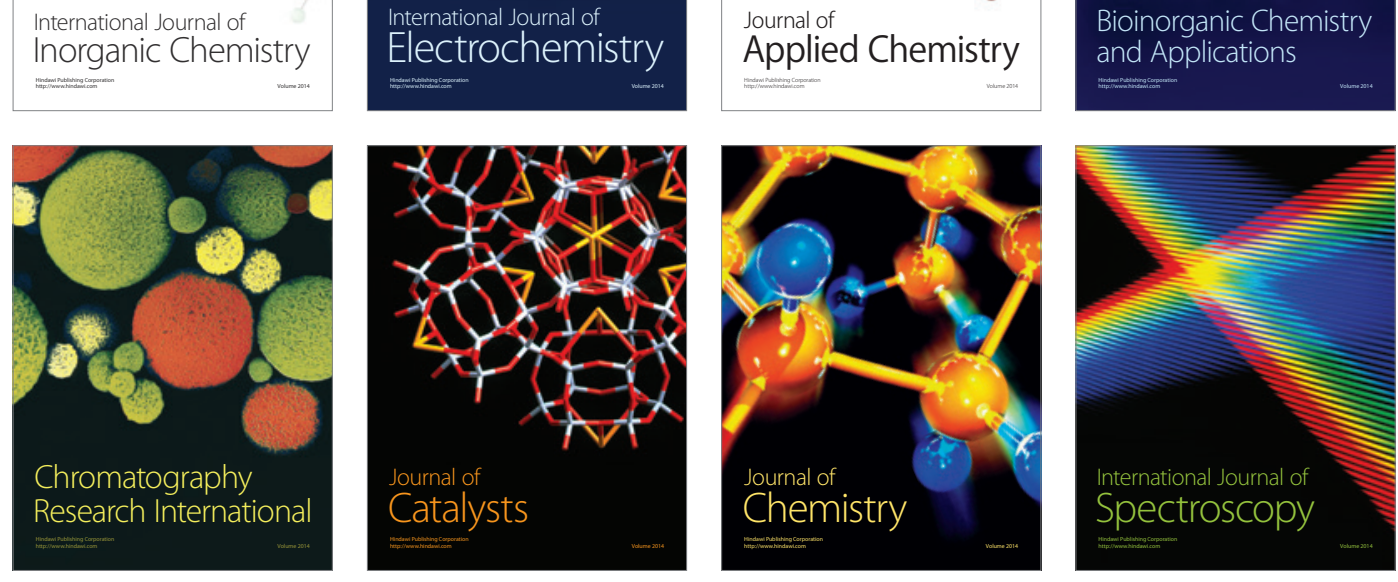